Article

\title{
Performance Evaluation and Investment Analysis for Container Port Sustainable Development in China: An Inverse DEA Approach
}

\author{
Yang Lin ${ }^{1} * \mathbb{C}$, Longzhong Yan ${ }^{1}$ and Ying-Ming Wang ${ }^{2}$ \\ 1 School of Economics, Fujian Normal University, Fuzhou 350117, China \\ 2 Decision Sciences Institute, Fuzhou University, Fuzhou 350108, China \\ * Correspondence: linyang@fjnu.edu.cn
}

Received: 12 July 2019; Accepted: 21 August 2019; Published: 25 August 2019

check for updates

\begin{abstract}
Container ports play an important role in international maritime trade. However, the rapid growth of the port and terminal industry has caused many environmental pollution problems. This paper intends to develop an inverse data envelopment analysis (IDEA) model for measuring container ports' efficiency and analyzing their resource consumption by considering undesirable outputs. Statistical data from 16 main ports are empirically examined using the proposed method in accordance with the 13th Five-Year Plan in China. The results indicate that the proposed IDEA is a feasible approach for performance evaluation, and provides policymakers with insights into resource optimization of container ports. A comparative study with another DEA model is also discussed.
\end{abstract}

Keywords: Inverse DEA; container ports; efficiency evaluation; investment analysis; undesirable output

\section{Introduction}

Nowadays, container ports serve a key role in achieving global logistics and supply chains. With the great opportunity of the Belt and Road Initiative (BRI), a Chinese grand economic plan launched in 2013, many countries invest a great number of resources into developing port terminals [1]. Accordingly, the construction of port facilities, the acceleration of port upgrading, the integration of green energy concepts, and so forth, are crucial for prompting port industry [2] and have been written into the Chinese 13th Five-Year Plan (FYP). China now has 15 ports listed in the top 50 world's ports and harbors in 2016 [3]. However, each port should have features of geographical location, deep-water berth, dispatching system, and pollution controlling, and such differences lead to different port efficiencies (advantages). An overall understanding of each port's competitiveness is not only beneficial for policymakers designing marine transports [1], but also useful in resource prediction or planning. On the other hand, however, the prosperity of the port industry is usually accompanied by much harmful pollution, such as greenhouse gas $\left(\mathrm{CO}_{2}\right)$ and toxic emissions (NOx, SOx). In response, many governments have initiated sustainable waterways planning and launched regulations to prevent environmental deterioration. Accordingly, the primary pollutants should be taken into consideration in the process of port efficiency evaluation and consumption analysis [4].

There have been many quantitative analysis techniques for performance measurement in management theory. Data envelopment analysis (DEA), as a nonparametric programming method, is one of the most popular tools in measuring efficiency for a set of decision-making units (DMUs) [5]. Classical DEA models (e.g., the CCR, BCC, cone ratio, SBM, allocative models) have been extensively applied in a wide range of areas including evaluations of $R \& D$ projects $[6]$, universities $[7,8]$, production systems [9], banks [10], environmental regulation [11,12], and so on. For further applications of DEA in decision analysis, Wei et al. [13] introduced a new DEA approach called inverse DEA (IDEA) to deal 
with a kind of investment optimization problem. Unfortunately, existing literature has rarely discussed the efficiency evaluation or investment analysis of container ports based on IDEA. Additionally, in efficiency analysis, traditional IDEA or DEA models often neglect the undesirable outputs, such as pollution and waste that usually are produced along with the desirable ones during a production process [14]. Therefore, the objective of this study is to suggest a novel IDEA model considering undesirable outputs to manage the performance evaluation and prediction of container ports.

The remainder of this paper is structured as follows. Section 2 presents a literature review and Section 3 introduces preliminaries. The proposed IDEA model with undesirable outputs is introduced in Section 4. Section 5 conducts an empirical study with some comparative analyses. Section 6 concludes this paper.

\section{Literature Review}

In this section, we firstly survey the DEA technique as well as its application in port evaluation. Then, we review some related studies on the inverse DEA.

DEA, originally proposed by Charnes et al. [5], utilizes multiple inputs to produce multiple outputs without parametric assumptions. The past 40 years have witnessed the appearance of a great number of studies on DEA theory and its application [15]. Tavares [16] listed more than 3000 references about DEA from 1978 to 2001, where 40\% of them were published in qualified journals. Using DEA to estimate the performances of container ports has aroused much attention in recent years. The pioneering work in port assessment using DEA was developed by Roll and Hayuth [17], based on the work of Tongzon [18], who proposed an additive CCR model for estimating several Australian ports and international ports. Wu and Liang [2] applied the DEA model under variable returns to rate (VRS) to evaluate the performance of 77 global ports (DMUs), and a benchmark was also established to improve the performance of inefficient DMUs. As for Asia ports, Itoh [19] employed the window BCC model to examine the efficiency variations of eight Japanese ports. The results showed a difference among port terminals with timely development. Hung et al. [20] combined traditional DEA models with the bootstrap method to estimate the operating performance of 31 main ports in Asia, which provided insight for resource allocation as well as procedure optimization. Dong et al. [21] evaluated the environmental performance and compared the operational efficiency of 10 Asian ports along the BRI using slack-based measures. Inspired by supply chain pattern, Bichou [22] applied the DEA technique to model the container-terminal system as a two-stage operational process and assessed the performances of combined port terminals.

With a boom in international maritime trade, however, exhaust gas emissions (i.e., $\mathrm{CO}_{2}, \mathrm{NOx}$, PM2.5) from shipping severely deteriorate the coastal air quality. Accordingly, many studies [11,23-27] have been conducted investigating the port efficiency with undesirable (bad) outputs from an environmental perspective. Seiford and Zhu [23] argued that undesirable outputs (or inputs) could be integrated into traditional DEA models by data transformation. Song et al. [11] reviewed the environmental efficiency evaluation based on DEA technique with undesirable output under small samples. In the context of ecological pollution, most researchers take air emissions into account as undesirable outputs in DEA models. Liu et al. [27] suggested a unified framework of several traditional DEA models considering both undesirable inputs and outputs under disposability assumptions. Sun et al. [28] developed a nonradial DEA preference mode for analyzing the operational efficiency of Chinese ports, where the NOx emission is represented as an undesirable output. Haralambides and Gujar [29] presented a novel eco-DEA model that evaluates both desirable and undesirable outputs $\left(\mathrm{CO}_{2}\right)$ of port service production in India. In order to improve the level of pure technical environmental efficiency, $\mathrm{Na}$ et al. [30] proposed an inseparable slacks-based measure (SBM) model to estimate the environmental efficiencies of eight harbors in China, which reveals that most ports exhibit too much exhaust emissions. By incorporating undesirable variables, Lee et al. [31] measured the environmental efficiency of several port cities using the SBM model, and concluded that Singapore and Busan are the most environmentally efficient. Based on the assumption of undesirable output weak disposability, 
Bian et al. [32] developed an interval SBM model to estimate regional energy efficiency, as well as $\mathrm{CO}_{2}$ emissions efficiencies. As random errors may exist in collected data, Wu et al. [33] defined the efficiency of DMUs within risk factors and offered a stochastic DEA method with undesirable outputs to handle random errors.

It has been known that DEA results depend heavily on the selection of input and output variables. However, little attention has been given to the issue of how changes of output (or input) would affect the data on the other side. Specifically, if a DMU alters its output (input), to what extent should its input (output) be changed to maintain the current efficiency level [34]? This question implicates the concept of inverse DEA (IDEA), a kind of optimization technique in the form of DEA. Wei et al. [13] presented a multiple objective linear programming (MOLP) to calculate the output levels for inefficient DMUs. Jahanshahloo et al. [35] indicated that the IDEA can effectively estimate the optimal level of inputs, or find out the input excesses of a DMU when preserving its efficiency. Similar to returns to scale in DEA, Lertworasirikul et al. [36] applied the IDEA model for resource allocation under variable returns to scale. Then, a Pareto-efficient solution was introduced to solve this problem. Later, Ghiyasi [34] had a comment on the use of MOLP in [36] and rectified the input estimation of the IDEA model. On the other hand, combining DEA with undesirable outputs is rare in the existing literature. Chen et al. [14] put forward an IDEA model with undesirable outputs to analyze the sustainable investment problem in China; some suggestions on investment schemes were then provided corresponding to the results. Based on the philosophy of IDEA, Wegener and Amin [37] developed an optimization model to reduce greenhouse gas emissions; Emrouznejad et al. [38] initialized a three-stage method to allocate $\mathrm{CO}_{2}$ emission quota.

Based on the literature review above, much research has been done to measure port efficiency by various DEA models. Some scholars have also paid attention to the IDEA approach, the inverse optimization of the DEA technique. Despite its explanatory power, no research has yet utilized IDEA to study the performance of container ports with undesirable outputs. This paper aims to establish an IDEA approach for measuring the ports' efficiency and predicting resource investment in the presence of undesirable outputs.

\section{Preliminaries}

\subsection{CCR Model}

Suppose there are $n$ DMUs, and each $\operatorname{DMU}_{j}(j=1,2, \ldots, n)$ utilizes $m$ inputs $x_{i}(i=1,2, \ldots, m)$ to produce $s$ outputs $y_{r j}(r=1,2, \ldots, s)$. For the $\mathrm{DMU}_{0}$ under evaluation, its efficiency score can be measured by the CCR model in envelopment form as follows [5]:

$$
\begin{array}{ll}
\min & \theta_{0} \\
\text { s.t. } & \sum_{j=1}^{n} \lambda_{j} x_{i j} \leq \theta_{0} x_{i 0}, \quad i=1,2, \ldots, m \\
& \sum_{j=1}^{n} \lambda_{j} y_{r j} \geq y_{r 0}, \quad r=1,2, \ldots, s \\
& \lambda_{j} \geq 0, \quad j=1,2, \ldots, n
\end{array}
$$

where $\theta_{0}$ is a real variable related to $\mathrm{DMU}_{0}$ and $\lambda=\left\{\lambda_{j} \mid j=1,2, \ldots, n\right\}$ is a non-negative vector. The above model is an estimation approach of constant returns to scale (CRS). We call $\mathrm{DMU}_{0} \mathrm{CCR}$-efficient if and only if $\theta_{0}=1$.

\subsection{Inverse DEA Model}

Let $\theta_{0}^{*}$ be the optimal value of $\mathrm{DMU}_{0}$ evaluated by the above CCR model. If we want to increase a certain output amount of $\mathrm{DMU}_{0}$, say $\Delta y_{0}$, from $y_{0}$ to $\beta_{0}$ where $\beta_{0}=y_{0}+\Delta y_{0}$, then inputs would have 
a corresponding change $\Delta x_{0}$ from $x_{0}$ to $\alpha_{0}$, and the following model can be established to estimate the minimum increment $\Delta x_{0}[34]$ :

$$
\begin{aligned}
\min & \Delta x_{0}=w^{T}\left(\Delta x_{10}, \Delta x_{20}, \ldots, \Delta x_{m 0}\right) \\
\text { s.t. } & \sum_{j=1}^{n} \lambda_{j} x_{i j}+\lambda_{0^{\prime}}\left(x_{i 0}+\Delta x_{i 0}\right) \leq \theta_{0}^{*}\left(x_{i 0}+\Delta x_{i 0}\right), i=1,2, \ldots, m \\
& \sum_{i=1}^{n} \lambda_{j} y_{i j}+\lambda_{0^{\prime}}\left(y_{r 0}+\Delta y_{r 0}\right) \geq y_{r 0}+\Delta y_{r 0}, r=1,2, \ldots, s \\
& x_{i 0}+\Delta x_{i 0} \geq 0, i=1,2, \ldots, m \\
& \lambda_{j}, \lambda_{0^{\prime}} \geq 0, j=1,2, \ldots, n
\end{aligned}
$$

where $\theta_{0}^{*}$ is the efficiency score solved by model (1) and $\boldsymbol{w}^{T}=\left(w_{1}, w_{2}, \ldots, w_{m}\right)$ is the weight vector of $\Delta x_{0}$. For any given $\Delta y_{0} \neq 0$, the above model can be equivalently solved by converting into model (3) as below,

$$
\begin{aligned}
\min & \Delta x_{0}=\boldsymbol{w}^{T}\left(\Delta x_{10}, \Delta x_{20}, \ldots, \Delta x_{m 0}\right) \\
\text { s.t. } & \sum_{i=1}^{n} \lambda_{j} x_{i j} \leq \theta_{0}^{*}\left(x_{i 0}+\Delta x_{i 0}\right), i=1,2, \ldots, m \\
& \sum_{i=1}^{n} \lambda_{j} y_{i j} \geq y_{r 0}+\Delta y_{r 0}, \quad r=1,2, \ldots, s \\
& \lambda_{j} \geq 0, \quad j=1,2, \ldots, n
\end{aligned}
$$

\section{Proposed IDEA Model}

\subsection{CCR Efficiency with Undesirable Outputs}

As aforementioned, efficiency assessment and investment analysis of container ports are quite important in promoting BRI. Every ship powered by fuel oil brings merchandise into a harbor characterized by high environmental pollution. An overall evaluation of a container port must take inputs and desirable and undesirable outputs into account. Assume each $\operatorname{DMU}_{j}(j=1,2, \ldots, n)$ to be evaluated against $m$ inputs $x_{i j}(i=1,2, \ldots, \mathrm{m}), s$ desirable outputs $y_{r j}(r=1,2, \ldots, s)$ and $g$ undesirable outputs $z_{l j}(l=1,2, \ldots, g)$. Firstly, we measure the efficiency scores of $n$ DMUs. When a DMU is allowed to alter its output level, it often assumes the original efficiency remains unchanged [13] especially when it is efficient. Note that model (1) cannot be directly applied to a production process involving undesirable output variables. Inspired by the work in [23], we extend the traditional CCR model involving both desirable and undesirable outputs, which is constructed as follows,

$$
\begin{array}{ll}
\min & \theta_{0} \\
\text { s.t. } & \sum_{j=1}^{n} \lambda_{j} x_{i j} \leq \theta_{0} x_{i 0}, \quad i=1,2, \ldots, m \\
& \sum_{j=1}^{n} \lambda_{j} y_{r j} \geq y_{r} 0, \quad r=1,2, \ldots, s \\
& \sum_{j=1}^{n} \lambda_{j} \bar{z}_{l j} \geq \bar{z}_{l 0}, \quad l=1,2, \ldots, g \\
& \lambda_{j} \geq 0, \quad j=1,2, \ldots, n
\end{array}
$$

In model (4), we turn the negative variable $-z_{l j}$ into a positive one $\bar{z}_{l j}$,

$$
\bar{z}_{l j}=-z_{l j}+\delta_{l, j}=1,2, \ldots, n
$$

where $\delta_{l}$ is a positive number such that $\delta_{l}=\max \left\{z_{l j}\right\}+1, j=1,2, \ldots, n$ [23]. Obviously, $\bar{z}_{l j}>0$ and a larger value of $\bar{z}_{l j}$ signifies a better output level. 


\subsection{Consumption Analysis by IDEA}

Let $\theta_{0}^{*}$ be the efficiency of $\mathrm{DMU}_{0}$ obtained by model (4). The essence of consumption analysis by inverse DEA, just as its name indicates, is assuming $\mathrm{DMU}_{0}$ has a perturbation in outputs at first, and finding out the required minimum changes in inputs. Notice that we still use $\bar{z}_{l j}$ instead of $z_{l j}$ in the IDEA model to make sure they are consistent with each other. Otherwise, the undesirable variables would be optimized in decreasing values which are contrary to the desirable ones. According to this idea, the IDEA model with the undesirable outputs (IDEAU) can be formulated as:

$$
\begin{array}{ll}
\min & \sum_{i=1}^{m} \Delta x_{i 0} \\
\text { s.t. } & \sum_{j=1}^{n} \lambda_{j} x_{i j} \leq \theta_{0}^{*}\left(x_{i 0}+\Delta x_{i 0}\right), i=1,2, \ldots, m \\
& \sum_{j=1}^{n} \lambda_{j} y_{r j} \geq y_{r 0}+\Delta y_{r 0}, r=1,2, \ldots, s \\
& \sum_{j=1}^{n} \lambda_{j} \bar{z}_{l j} \geq \bar{z}_{l 0}+\Delta z_{l 0}, l=1,2, \ldots, g \\
& \lambda_{j} \geq 0, j=1,2, \ldots, n \\
& \Delta x_{i 0} \text { unrestrictedinsign }
\end{array}
$$

where $x_{i 0}$ and $y_{r 0}(i=1,2, \ldots m, r=1,2, \ldots, s)$ are respectively the input and desirable output variables. $\bar{z}_{l 0}$ is the undesirable output variable converted by $z_{l 0}(l=1,2, \ldots, g)$, while $\Delta y_{r 0}$ and $\Delta z_{l 0}$ are the given changed amount. All $\Delta x_{i}(i=1,2, \ldots, m)$ are treated as equally important in the objective function, as they have the same weights. Note that $\Delta x_{i}(i=1,2, \ldots, m)$ are allowed to be negative as long as their combination satisfies the constraints in model (6).

Theorem 1. For given changes $\Delta y_{r 0} \neq 0$ and $\Delta z_{10} \neq 0$ in desirable and undesirable outputs of $D M U_{0}$, respectively. The minimum input alternation $\Delta x_{i 0}$ can be derived by model (6) while the efficiency $\theta_{0}^{*}$ remains unchanged.

The proof of Theorem 1 is similar to the proof of the theorem in [34] by using the definition of weak efficient solution.

\subsection{Performance Improvement by IDEA}

According to model (6), the minimum input changes of efficient DMUs can be estimated under the new given outputs. On the other hand, we can also identify the relative input excesses for inefficient DMUs by resetting the efficiency score as $\theta_{0}=1$, under the current output capacity. This leads to another version of the IDEAU model:

$$
\begin{array}{ll}
\max & \sum_{i=1}^{m} \Delta x_{i 0} \\
\text { s.t. } & \sum_{j=1}^{n} \lambda_{j} x_{i j} \leq x_{i 0}-\Delta x_{i 0}, \quad i=1,2, \ldots, m \\
& \sum_{j=1}^{n} \lambda_{j} y_{r j} \geq y_{r 0}, \quad r=1,2, \ldots, s \\
& \sum_{j=1}^{n} \lambda_{j} z_{l j} \geq \bar{z}_{l 0}, \quad l=1,2, \ldots, g \\
& \lambda_{j} \geq 0, \quad j=1,2, \ldots, n \\
& \Delta x_{i 0} \text { unrestricted in sign }
\end{array}
$$

It should be pointed out that model (7) may be infeasible to some DMUs in optimizing resource consumption since there seems to be a dilemma that regulates desirable and undesirable outputs at the same time. Intuitively, decreasing gas emissions may be accompanied by an effort of reducing resource 
inputs, which usually results in lower (desirable) production quantity. However, it is not allowed to reduce the current level of outputs.

According to the aforementioned analyses, the evaluation process of the proposed IDEAU method is graphically depicted in Figure 1.

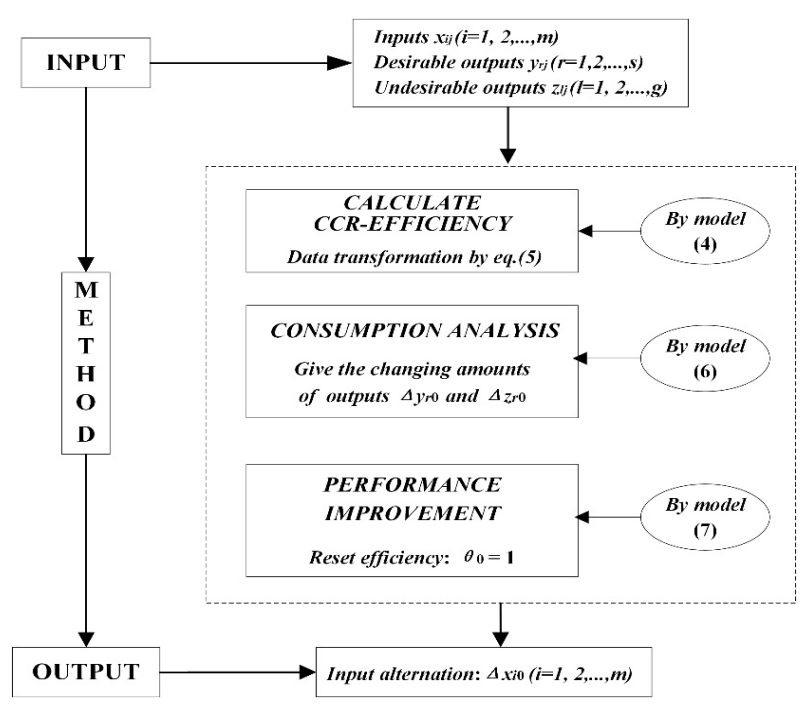

Figure 1. Evaluation process of the proposed method.

\section{Empirical Research}

In this section, an empirical case about 16 Chinese container ports (Ningbo, Shanghai, Tianjin, Tangshan, Dalian, Rizhao, Yingkou, Nanjing, Xiamen, Lianyungang, Chongqing, Yantian, Shenzhen, Zhuhai, Jinzhou, and Fuzhou) in 2017 is studied. These container ports are ranked in the top 20 in China according to the annual throughputs, which have a significant impact on the strategy of Chinese BRI. Figure 2 shows geographical information about these ports. The Chinese government enacted the 13th FYP (2016-2020) in 2016. The blueprint for economic and social development grabs the general public's attention. As to the Transport sector of the 13th FYP in China, port construction is a hot issue under the big opportunity of BRI; issues like consumption prediction or optimization analysis have aroused people's concern.

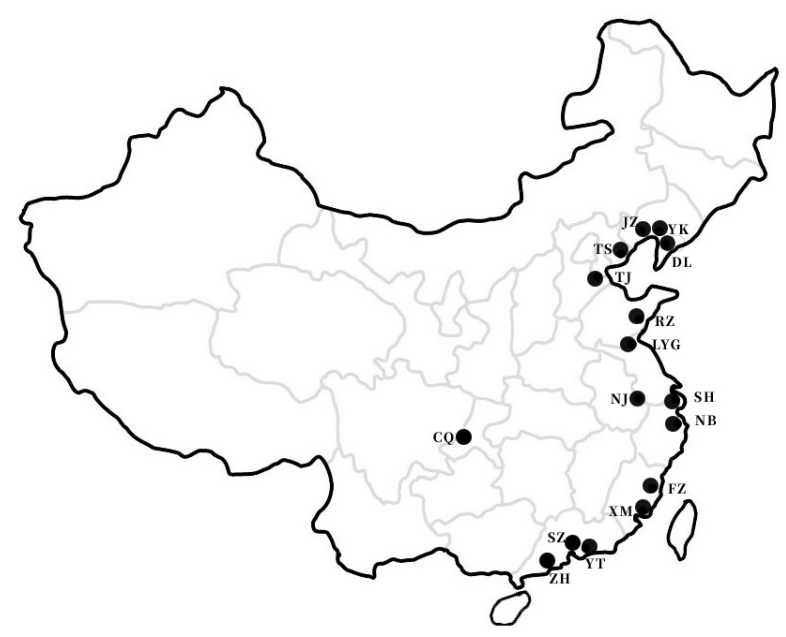

Figure 2. Distribution of sixteen Chinese ports. 


\subsection{Data Description}

In this study, berth length $\left(x_{1}\right)$, equipment asset $\left(x_{2}\right)$, number of employees $\left(x_{3}\right)$, and cost $\left(x_{4}\right)$ are used as four input variables, and throughput $\left(\mathrm{y}_{1}\right)$, profit $\left(\mathrm{y}_{2}\right)$ are two desirable output variables while emission amount of $\mathrm{CO}_{2}\left(\mathrm{z}_{1}\right)$ and $\mathrm{NOx}\left(\mathrm{z}_{2}\right)$ are two undesirable output variables. The data of these criteria were taken from Chinese ports yearbook [39] and the published work in Lai et al. [40], which are documented in Table 1. Nevertheless, the statistics about $\mathrm{CO}_{2}$ and $\mathrm{NOx}$ are unavailable to collect directly from the existing reference. Thus, we estimate these emissions using two specific formulas shown in Appendix A.

Table 1. Statistics of the 16 ports in 2017.

\begin{tabular}{ccccccccc}
\hline \multirow{2}{*}{ Port } & Berth & Equipment & Employee & Cost & Throughput & Profit & CO $_{2}$ & NO $_{\mathbf{x}}$ \\
\cline { 2 - 9 } & Units & Million * & Units & Million * & Million Tons & Million * & Tons & Tons \\
\hline NB & 615 & 5390 & 1170 & 14,026 & 91,800 & 2299 & 59.05 & 1.18 \\
SH & 608 & 5560 & 1830 & 24,420 & 70,000 & 6939 & 45.03 & 1.13 \\
TJ & 162 & 2530 & 760 & 11,783 & 55,000 & 1264 & 35.38 & 0.88 \\
TS & 77 & 3340 & 270 & 4306 & 51,600 & 1320 & 37.00 & 1.23 \\
DL & 240 & 1090 & 680 & 12283 & 42,900 & 531 & 28.65 & 0.57 \\
RZ & 52 & 1660 & 160 & 5101 & 53,100 & 176 & 24.30 & 0.61 \\
YK & 87 & 160 & 490 & 2208 & 34,700 & 353 & 22.32 & 0.45 \\
NJ & 69 & 30 & 70 & 138 & 21,700 & 85 & 13.96 & 0.31 \\
XM & 173 & 360 & 390 & 8785 & 20,900 & 207 & 8.22 & 0.10 \\
LYG & 62 & 810 & 460 & 869 & 20,200 & 7.0 & 13.99 & 0.28 \\
CQ & 191 & 670 & 220 & 2121 & 17,200 & 78 & 9.37 & 0.19 \\
YT & 20 & 60 & 50 & 141 & 10,900 & 352 & 7.01 & 0.14 \\
SZ & 25 & 650 & 170 & 137.3 & 10,600 & 532 & 6.82 & 0.14 \\
ZH & 153 & 133 & 200 & 169.7 & 9000 & 104 & 4.78 & 0.08 \\
JZ & 23 & 149 & 15 & 249.7 & 8900 & 56 & 5.07 & 0.10 \\
FZ & 120 & 320 & 260 & 705.1 & 15,800 & 293 & 8.39 & 0.12 \\
\hline
\end{tabular}

\subsection{Performance Evaluation of Container Ports}

We firstly use model (4) to measure the efficiencies of the 16 container ports (DMUs), and depict the results in Figure 3. Clearly, there are four container ports (TS, RZ, NJ, YT) evaluated as CCR-efficient with a score of 1.0, while seven ports with the lowest scores are NB (0.234), DL (0.324), XM (0.239), LYG (0.241), CQ (0.266), ZH (0.099), and FZ (0.195), all having a score below 0.4. Besides, other inefficient DMUs are JZ (0.904), YK (0.708), TJ (0.571), SZ (0.448), and SH (0.473), which are ranked in descending order.

We classify and discuss these ports (DMUs) in two categories according to their efficiency scores. As to the four efficient DMUs, we utilize model (5) to optimize the input consumption with a given output level. To do so, we estimate the variation in output level at the target year first. According to the Transport sector of the 13th FYP in China and the Eco-Environmental Protection of the 13th FYP [41], the expected throughput and the expected growth rate of profit for the four ports in 2020 can be approximately derived. Moreover, the estimation of the expected profit growth rate refers to their financial reports for the years between 2015 and 2017. The plan also sets a general target for decreasing pollutant emissions such as $\mathrm{CO}_{2}$ and NOx. The relevant data are listed in Table 2.

Combined with model (5) and the data stored in Table 2, we can establish the IDEAU model for consumption predictions. The excepted investment optimization corresponding to the given development targets for the four efficient DMUs are listed in Table 3.

On the other hand, as to the twelve inefficient DMUs, we apply model (7) to estimate the potential input excesses of them to improve their productivity. We find the six container ports of NB, DL, LYG, SZ, JZ, and FZ can be improved by disinvesting, as shown in Table 4. As to the other six ports, namely, 
$\mathrm{SH}, \mathrm{TJ}, \mathrm{YK}, \mathrm{XM}, \mathrm{CQ}$, and $\mathrm{ZH}$, there are no feasible solutions for them since the constraints in model (7) are quite strict for the variables $y_{r 0}$ and $\bar{z}_{l 0}$ that are optimized in opposite directions.

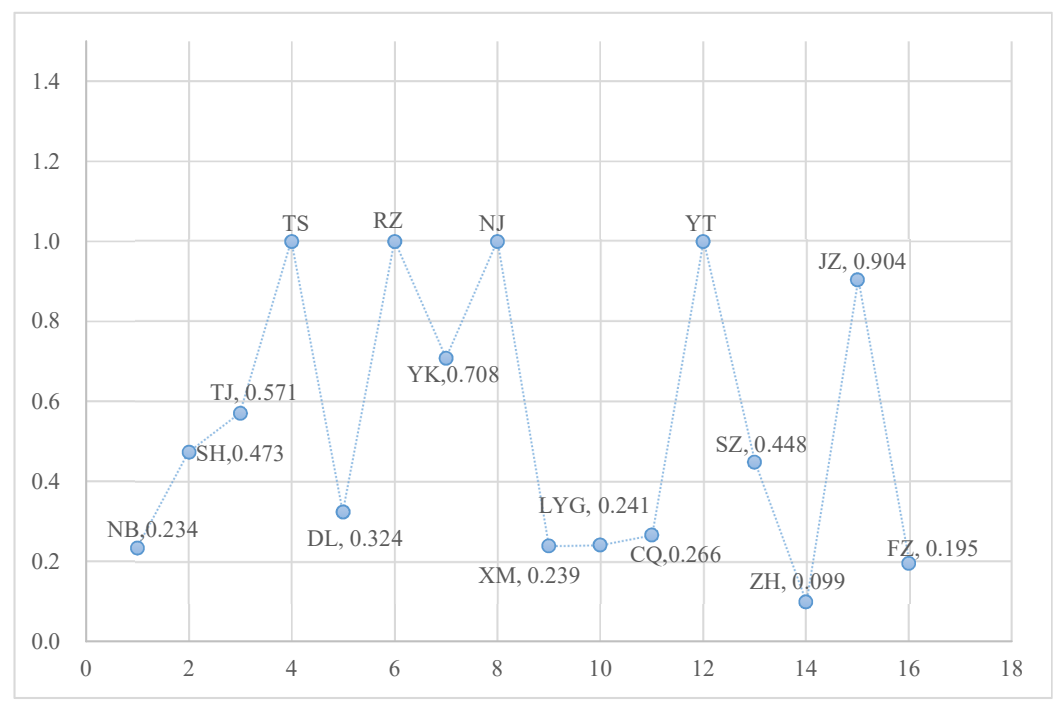

Figure 3. CCR efficiencies of the 16 ports.

Table 2. Expected changes of the four ports in 2020.

\begin{tabular}{ccccc}
\hline \multirow{2}{*}{ Port } & \multicolumn{4}{c}{ Output Variation } \\
\cline { 2 - 4 } & $\Delta y_{1}$ & $\Delta y_{2}$ & $\Delta z_{1}$ & $\Delta z_{2}$ \\
\hline TS & $11.2 \%$ & $6.84 \%$ & $-7.0 \%$ & $-8.7 \%$ \\
RZ & $15.0 \%$ & $2.57 \%$ & $-7.0 \%$ & $-8.1 \%$ \\
NJ & $6.1 \%$ & $1.58 \%$ & $-3.6 \%$ & $-6.0 \%$ \\
YT & $5.8 \%$ & $5.28 \%$ & $-3.3 \%$ & $-2.5 \%$ \\
\hline
\end{tabular}

Table 3. Input predictions of the four ports.

\begin{tabular}{ccccc}
\hline \multirow{2}{*}{ Port } & \multicolumn{4}{c}{ Inputs } \\
\cline { 2 - 5 } & Berth $\left(\Delta \boldsymbol{x}_{1}\right)$ & Equipment ${ }^{*}\left(\boldsymbol{\Delta} \boldsymbol{x}_{2}\right)$ & ${\text { Employee }\left(\boldsymbol{\Delta} \boldsymbol{x}_{3}\right)}$ & Cost $^{*}\left(\boldsymbol{\Delta} \boldsymbol{x}_{4}\right)$ \\
\hline TS & 12 & -42.2 & 1 & -4.7 \\
RZ & 4 & -14.6 & 33 & -1.8 \\
NJ & 0 & 4.71 & 1 & 7.5 \\
YT & 0 & 12.1 & 0 & 3.1 \\
\hline
\end{tabular}

Note: * The monetary unit is million RMB.

Table 4. Potential input excesses of six ports.

\begin{tabular}{ccccc}
\hline \multirow{2}{*}{ Port } & \multicolumn{4}{c}{ Inputs } \\
\cline { 2 - 5 } & Berth $\left(\boldsymbol{\Delta} \boldsymbol{x}_{1}\right)$ & Equipment $\left(\boldsymbol{\Delta x _ { 2 } )}\right.$ & Employee $\left(\boldsymbol{\Delta} \boldsymbol{x}_{3}\right)$ & Cost $\left(\boldsymbol{\Delta} \boldsymbol{x}_{4}\right)$ \\
\hline NB & 112.6 & 390.8 & 58 & 0.0 \\
DL & 77.2 & 178.9 & 92 & 837.8 \\
LYG & 0.0 & 76.3 & 37 & 50.4 \\
SZ & 0.0 & 52.6 & 18 & 11.5 \\
JZ & 0.0 & 53.8 & 2 & 8.1 \\
FZ & 24.5 & 76.6 & 35 & 259.2 \\
\hline
\end{tabular}




\subsection{Results Analysis}

It is found in Table 3 that some values are negative, which indicates a reduction in the amount of input. This is because we do not put a restraint on $\Delta x_{i}(i=1,2,3,4)$, as shown in model (6), to avoid being unsolved for each DMU under evaluation. The results suggest increasing 12 berths and 4 berths for TS and RZ, respectively, whereas the equipment investment and cost can be cut down. This means the carrying capacity of the two ports, especially TS, have not been fully utilized. For the NJ and TY ports, it suggests to invest more capital on equipment $\left(\Delta x_{2}\right)$ and cost $\left(\Delta x_{4}\right)$ without increasing the number of berths. For the input element of $\Delta x_{3}$, only the RZ port has a striking number of hiring an additional 33 qualified persons. This advice sounds reasonable because the employees in the RZ port are too few to ensure efficient operation as related to the number of 52 berths.

Table 4 demonstrates the input excesses of six inefficient DMUs. In DEA literature, another popular technique for measuring input excesses of DMUs is the slacks-based model (SBM) [31,42]. To verify the obtained results, we empirically conducted a comparison between the SBM model with undesirable outputs (SBMU) [31] and the proposed IDEAU model. The results are depicted in Table 5, which only lists the same six ports for comparison with Table 4.

Table 5. The input excesses by SBMU model.

\begin{tabular}{cccccc}
\hline \multirow{2}{*}{ Port } & \multicolumn{3}{c}{ Inputs } & \multicolumn{2}{c}{ Score } \\
\cline { 2 - 6 } & $\boldsymbol{\Delta} \boldsymbol{x}_{1}$ & $\boldsymbol{\Delta} \boldsymbol{x}_{2}$ & $\boldsymbol{\Delta} \boldsymbol{x}_{3}$ & $\boldsymbol{\Delta} \boldsymbol{x}_{4}$ & \\
\hline NB & 246.6 & 488.4 & 74 & 283.8 & 0.189 \\
DL & 161.3 & 453.8 & 283 & 1172.8 & 0.154 \\
LYG & 24.9 & 298.8 & 167 & 60.7 & 0.028 \\
SZ & 0.0 & 0.0 & 0.0 & 0.0 & 1.00 \\
JZ & 0.0 & 0.0 & 0.0 & 0.0 & 1.00 \\
FZ & 20.52 & 85.98 & 32 & 241.8 & 0.754 \\
\hline
\end{tabular}

Obviously, the values in Table 5 are generally greater than those in Table 4, except for the FZ port. Moreover, Both SZ and JZ ports are evaluated as efficient DMUs by the SBMU method, but inefficient by the IDEAU model. Nevertheless, we observe the relative changing amounts of the three ports (NB, DL, LYG) are consistent with the two models. Although the two models are all categorized to nonradial measure, they are much different in modeling mechanism and objective target. Firstly, the objective of model (7) is to calculate how the maximum amounts of input excesses can be altered at the current level of outputs, while the latter aims to minimize the ratio of input and output mix inefficiencies [43]. Secondly, the model (7) is input-oriented and pursues the minimum investments in inputs while maintaining the output, yet the SBMU method is nonoriented and applies the input and output slacks in deriving an efficiency measure directly. Thirdly, we allow the variables in model (7) to be negative owing to the fact that the investment of an input factor may be rising or falling according to the future productivity scheme.

As to this case, we employ four input variables and four output variables, which seem too high compared to the number of 16 DMUs. Just as suggested by Boussofiane et al. [44], the number of input and output variables in DEA analysis should have better less than one-third the number of DMUs. Then, we remove the undesirable output variables $\left(z_{1}\right.$ and $\left.z_{2}\right)$ to verify the robustness of the results. Solving by model (4), the efficiency scores of nine ports (NB, SH, TS, RZ, YK, NJ, CQ, YT, SZ) are equal to 1 , which is different from the previous result that only four ports (TS, RZ, NJ, YT) are efficient as shown in Figure 3. We now focus on the investment analysis of the four ports (TS, RZ, NJ, YT), which are evaluated as CCR-efficient before and after removing the two undesirable variables. Perturbing their output level of desirable variables according to Table 2, the input predictions can be calculated based on the IDEAU model. The comparison is shown in Figure 4, where the left histogram is generated with the constraint of undesirable output variables. 


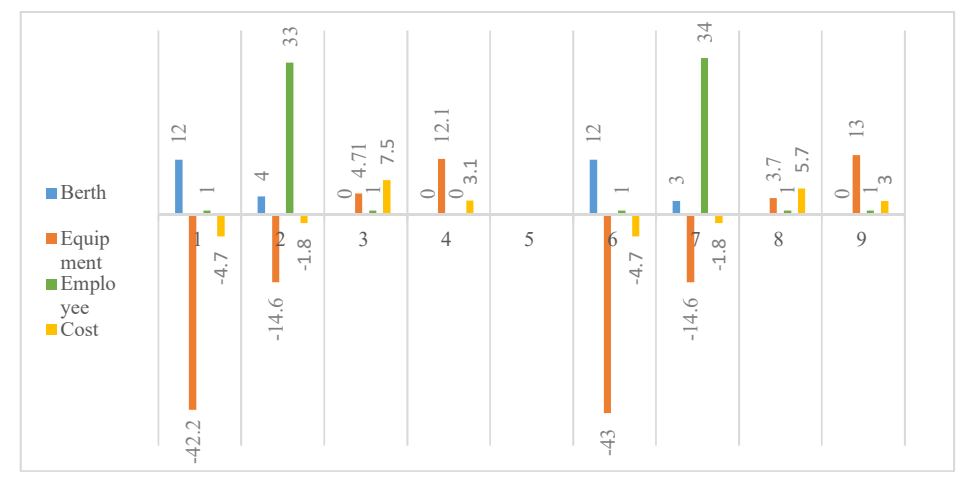

Figure 4. Comparison of input predictions of the four ports.

Generally, the alterations of input levels are quite similar from Figure 4. In other words, despite removing undesirable output variables, the changing amounts of inputs solved by the IDEAU model are consistent with the previous data in Table 3.

As per the empirical results, some policy suggestions are presented for promoting the container ports' sustainable development as follows:

(1) According to Figure 3, the average operational efficiency of the 16 Chinese ports is 0.544 , which is generally low and uncompetitive in global trade. Additionally, unbalanced development of main ports is a barrier to the maritime industry, where the ports around Bohai Sea including TS, JZ, YK, and DL ports have a relatively high performance. This region is highly exhaust polluted, and extra efforts should be made to control air emissions.

(2) Resource investments on the ports of NB, DL, LYG, and FZ should be further optimized to enhance their competitiveness. For instance, it is suggested to add 112 berths in the NB port or to invest more than 800 million in the DL port according to Table 4. As China's economy has entered a "new normal" that shows a marked slowdown, local government should upgrade the port industry by switching from resource-dependent mode to resource-friendly mode.

(3) The Yangtze River port system, which includes the NJ, NB, and SH ports, in this case, is an essential container system in China. The total throughput of the SH and NB ports exceeded 1.6 billion tons in 2017. Yet the CCR efficiencies of the two ports are not high when considering undesirable output factors. Taking the NB port as an example, the investments on berth and equipment need to reduce by 112 (units) and 390.8 (million), respectively. Besides, local policymakers should find a balance between ports' development and environmental protection since these ports contribute to a vast amount of exhaust emissions.

(4) As a key area in the BRI, Fujian province has great potential in the international logistics market. However, the XM and FZ ports in Fujian have low efficiency scores (0.239 and 0.195, respectively) compared to the other domestic ports. From Table 4, it is imperative for the FZ port to cut down costs in the future. Other effective policies, such as establishing a green port supply chain or regional linkage system, should be made.

\section{Conclusions}

Understanding of various main ports is quite crucial for Chinese authorities. The accelerating development of the port industry has caused widespread environmental pollution. Thus, the evaluation of ports efficiency should consider both desirable and undesirable outputs, which contribute to formulating achievable industrial policies. This paper develops a novel IDEA model to assess 16 Chinese ports' efficiency in 2017 by taking undesirable output into consideration. Then, analyses of ports' resource consumption are conducted according to the Chinese 13th FYP. We also discuss the improvement of inefficient ports (DMUs) by measuring their input excesses based on the proposed model. Overall, the IDEA approach for performance assessment and resource investment of ports has 
the following characteristics: (1) Both desirable and undesirable outputs can be incorporated in the proposed inverse DEA model; (2) the proposed method can be used to predict resource investments of a container port when given an output target; (3) by resetting the current efficiency score, the proposed method can measure the excess amounts of inputs of container ports.

However, this study has some limitations. First, we utilize the CCR model with undesirable outputs in calculating the efficiencies of DMUs. However, this classical model has low discriminating power in ranking efficient DMUs. Also, the data on emissions was not accessible but obtained indirectly. For future studies, other efficiency measures such as super-efficiency or cross-efficiency may be applied and integrated with the IDEA method. Another interesting research is to extend the proposed approach to deal with a more general port system with a multistage structure.

Author Contributions: Y.L., L.Y., and Y.-M.W. conceived, designed, and prepared the paper together.

Funding: This research was funded by the National Social Science Foundation of China under grant number (19BGL092).

Acknowledgments: The authors would like to thank the editor and anonymous reviewers. Their comments are valuable for us to improve the quality of this article.

Conflicts of Interest: No potential conflict of interest was reported by the authors.

\section{Appendix A}

1. $\mathrm{CO}_{2}$ emission:

The calculation of $\mathrm{CO}_{2}$ emissions is based on the relationship between port throughput and energy consumption [30]. The formula of $\mathrm{CO}_{2}$ emissions is as follows:

$$
E_{\mathrm{CO}_{2}}=N_{c} \times T \times \xi
$$

where $E_{\mathrm{CO}_{2}}$ is the amount of $\mathrm{CO}_{2}$ emissions, $N_{c}$ is unit consumption of standard coal, $T$ is port throughput, and $\xi$ is the parameter of carbon emissions that equals to 2.458 .

2. $\mathrm{NO}_{\mathrm{x}}$ emission:

The calculation of $\mathrm{NO}_{\mathrm{x}}$ emissions is simplified in our study and mainly refers to the amount of $\mathrm{CO}_{2}$ emissions and other parameters. The $\mathrm{NO}_{\mathrm{x}}$ emissions are calculated as follows:

$$
E_{\mathrm{NO}_{\mathrm{X}}}=E_{\mathrm{CO}_{2}} \times \psi \times \kappa
$$

where $E_{N O_{X}}$ is the amount of $\mathrm{NO}_{\mathrm{x}}$ emissions, $\psi$ is the ratio related to $\mathrm{CO}_{2}$ emissions, and $\kappa$ is fuel burning rate.

\section{References}

1. Ren, J.; Liang, D.; Lu, S. Competitiveness prioritisation of container ports in Asia under the background of China's Belt and Road initiative. Transp. Rev. 2018, 38, 1-21. [CrossRef]

2. $\mathrm{Wu}, \mathrm{J}$.; Liang, L. Performances and benchmarks of container ports using data envelopment analysis. Int. J. Shipp. Transp. Logist. 2009, 1, 295-310. [CrossRef]

3. World Shipping Council. Top 50 World Container Ports. Available online: http://www.worldshipping.org/ about-the-industry/global-trade/top-50-world-container-ports (accessed on 25 August 2019).

4. Dragović, B.; Tzannatos, E.; Tselentis, V.; Meštrović, R.; Škurić, M. Ship emissions and their externalities in cruise ports. Transp. Res. Part D 2018, 61, 289-300. [CrossRef]

5. Charnes, A.; Cooper, W.W.; Rhodes, E. Measuring the efficiency of decision making units. Eur. J. Oper. Res. 1978, 2, 429-444. [CrossRef]

6. Linton, J.D.; Walsh, S.T.; Morabito, J. Analysis, ranking and selection of R\&D projects in a portfolio. RED Manag. 2002, 32, 139-148. 
7. Kuah, C.T.; Wong, K.Y. Efficiency assessment of universities through data envelopment analysis. Proced. Comput. Sci. 2011, 3, 499-506. [CrossRef]

8. Sagarra, M.; Mar-Molinero, C.; Agasisti, T. Exploring the efficiency of Mexican universities: Integrating data envelopment analysis and multidimensional scaling. Omega 2017, 67, 123-133. [CrossRef]

9. Esmaeilzadeh, A.; Matin, R.K. Multi-Period efficiency measurement of network production systems. Measurement 2019, 134, 835-844. [CrossRef]

10. LaPlante, A.E.; Paradi, J.C. Evaluation of bank branch growth potential using data envelopment analysis. Omega 2015, 52, 33-41. [CrossRef]

11. Song, M.; An, Q.; Zhang, W.; Wang, Z.; Wu, J. Environmental efficiency evaluation based on data envelopment analysis: A review. Renew. Sustain. Energy Rev. 2012, 16, 4465-4469. [CrossRef]

12. Zhang, J.; Li, H.; Xia, B.; Skitmore, M. Impact of environment regulation on the efficiency of regional construction industry: A 3-Stage Data Envelopment Analysis (DEA). J. Clean. Prod. 2018, 200, 770-780. [CrossRef]

13. Wei, Q.; Zhang, J.; Zhang, X. An inverse DEA model for inputs/outputs estimate. Eur. J. Oper. Res. 2000, 121, 151-163. [CrossRef]

14. Chen, L.; Wang, Y.; Lai, F.; Feng, F. An investment analysis for China's sustainable development based on inverse data envelopment analysis. J. Clean Prod. 2017, 142, 1638-1649. [CrossRef]

15. Barat, M.; Tohidi, G.; Sanei, M.; Razavyan, S. Data envelopment analysis for decision making unit with nonhomogeneous internal structures: An application to the banking industry. J. Oper. Res. Soc. 2019, 70, 760-769. [CrossRef]

16. Tavares, G. A bibliography of data envelopment analysis (1978-2001). RUTCOR Rutgers Univ. 2002, 11, 14.

17. Roll, Y.; Hayuth, Y. Port performance comparison applying data envelopment analysis (DEA). Marit. Policy Manag. 1993, 20, 153-161. [CrossRef]

18. Tongzon, J. Efficiency measurement of selected Australian and other international ports using data envelopment analysis. Transp. Res. Part A 2001, 35, 107-122. [CrossRef]

19. Itoh, H. Effeciency changes at major container ports in Japan: A window application of data envelopment analysis. Rev. Urban Reg. Dev. Stud. 2002, 14, 133-152. [CrossRef]

20. Hung, S.W.; Lu, W.M.; Wang, T.P. Benchmarking the operating efficiency of Asia container ports. Eur. J. Oper. Res. 2010, 203, 706-713. [CrossRef]

21. Dong, G.; Zhu, J.; Li, J.; Wang, H.; Gajpal, Y. Evaluating the Environmental Performance and Operational Efficiency of Container Ports: An Application to the Maritime Silk Road. Int. J. Environ. Res. Public Health 2019, 16, 2226. [CrossRef]

22. Bichou, K. A two-Stage supply chain DEA model for measuring container-Terminal efficiency. Int. J. Shipp. Transp. Logist. 2011, 3, 6-26. [CrossRef]

23. Seiford, L.M.; Zhu, J. Modeling undesirable factors in efficiency evaluation. Eur. J. Oper. Res. 2002, 142, 16-20. [CrossRef]

24. Zhou, P.; Ang, B.W.; Poh, K.L. A survey of data envelopment analysis in energy and environmental studies. Eur. J. Oper. Res. 2008, 189, 1-18. [CrossRef]

25. Wang, K.; Wei, Y.M. China's regional industrial energy efficiency and carbon emissions abatement costs. Appl. Energy 2014, 130, 617-631. [CrossRef]

26. Piao, S.R.; Li, J.; Ting, C.J. Assessing regional environmental efficiency in China with distinguishing weak and strong disposability of undesirable outputs. J. Clean. Prod. 2019, 227, 748-759. [CrossRef]

27. Liu, W.B.; Meng, W.; Li, X.X.; Zhang, D.Q. DEA models with undesirable inputs and outputs. Ann. Oper. Res. 2010, 173, 177-194. [CrossRef]

28. Sun, J.; Yang, Y.; Rui, Y.; Xiang, J.; Wu, J. Performance evaluation of Chinese port enterprises under significant environmental concerns: An extended DEA-Based analysis. Transp. Policy 2017, 60, 75-86. [CrossRef]

29. Haralambides, H.; Gujar, G. On balancing supply chain efficiency and environmental impacts: An eco-DEA model applied to the dry port sector of India. Marit. Econ. Logist. 2012, 14, 122-137. [CrossRef]

30. Na, J.H.; Choi, A.Y.; Ji, J.; Zhang, D. Environmental efficiency analysis of Chinese container ports with $\mathrm{CO}_{2}$ emissions: An inseparable input-Output SBM model. J. Transp. Geogr. 2017, 65, 13-24. [CrossRef]

31. Lee, T.; Yeo, G.T.; Thai, V.V. Environmental efficiency analysis of port cities: Slacks-Based measure data envelopment analysis approach. Transp. Policy 2014, 33, 82-88. [CrossRef] 
32. Bian, Y.; Lv, K.; Yu, A. China's regional energy and carbon dioxide emissions efficiency evaluation with the presence of recovery energy: An interval slacks-Based measure approach. Ann. Oper. Res. 2017, 255, 301-321. [CrossRef]

33. Wu, C.; Li, Y.; Liu, Q.; Wang, K. A stochastic DEA model considering undesirable outputs with weak disposability. Math. Comput. Model. 2013, 58, 980-989. [CrossRef]

34. Ghiyasi, M. On inverse DEA model: The case of variable returns to scale. Comput. Ind. Eng. 2015, 87, 407-409. [CrossRef]

35. Jahanshahloo, G.R.; Lotfi, F.H.; Shoja, N.; Tohidi, G.; Razavyan, S. Input estimation and identification of extra inputs in inverse DEA models. Appl. Math. Comput. 2004, 156, 427-437. [CrossRef]

36. Lertworasirikul, S.; Charnsethikul, P.; Fang, S.C. Inverse data envelopment analysis model to preserve relative efficiency values: The case of variable returns to scale. Comput. Ind. Eng. 2011, 61, 1017-1023. [CrossRef]

37. Wegener, M.; Amin, G.R. Minimizing greenhouse gas emissions using inverse DEA with an application in oil and gas. Expert Syst. Appl. 2019, 122, 369-375. [CrossRef]

38. Emrouznejad, A.; Yang, G.; Amin, G.R. A novel inverse DEA model with application to allocate the $\mathrm{CO}_{2}$ emissions quota to different regions in Chinese manufacturing industries. J. Oper. Res. Soc. 2019, 70, 1079-1090. [CrossRef]

39. Chinese Ports Yearbook; National Bureau of Statistics of China: Beijing, China, 2018.

40. Lai, C.S.; Lu, J.; Li, X.Q. Port production efficiency research based on two-Stage DEA game cross efficiency model. J. Shanghai Marit. Univ. 2018, 39, 52-59.

41. Chinese State Council. 13th Five-Year Plan for Eco-Environmental Protection 2016. Available online: http://www.gov.cn/zhengce/content/2016-12/05/content_5143290.htm (accessed on 25 August 2019).

42. Tone, K. A slacks-Based measure of efficiency in data envelopment analysis. Eur. J. Oper. Res. 2001, 130, 498-509. [CrossRef]

43. Cooper, W.W.; Seiford, L.M.; Tone, K. Introduction to Data Envelopment Analysis and Its Uses: With DEA-Solver Software and References; Springer Science \& Business Media: New York, NY, USA, 2006.

44. Boussofiane, A.; Dyson, R.G.; Thanassoulis, E. Applied data envelopment analysis. Eur. J. Oper. Res. 1991, 52, 1-15. [CrossRef] 